\title{
The Impact of Intrahousehold Resource Distribution on Woman's Bargaining Power - A Collective Model Approach
}

\author{
Syed Ali, Bupe Simuchimba, Christabel Ngongola \\ Department of Economics, Mulungushi University, Kabwe, Zambia \\ Email address: \\ profali_1951@yahoo.com (S. Ali), bupesimuchimba@yahoo.co.uk (B. Simuchimba), christabel.ngongola@gmail.com (C. Ngongola)
}

\section{To cite this article:}

Syed Ali, Bupe Simuchimba, Christabel Ngongola. The Impact of Intrahousehold Resource Distribution on Woman's Bargaining Power - A Collective Model Approach. International Journal of Economics, Finance and Management Sciences. Vol. 6, No. 1, 2018 , pp. $27-34$. doi: 10.11648/j.ijefm.20180601.15

Received: January 30, 2018; Accepted: February 16, 2018; Published: March 16, 2018

\begin{abstract}
This study was conducted in Kabwe city of Zambia during June to august 2017. The city was divided in to three zones - more developed, medium developed and backward. From each zone one area, i.e., Highridge, Katundo and Makululu, respectively, was selected. The purpose of study was to know the impact of intra-household resource distribution on woman's bargaining power. Logit model was used to find out the relationship between dependent and independent variables. The study revealed positive impact of age and education on bargaining power of woman in the household. Asset ownership also had significant impact on the bargaining power of woman. The study recommended to constitute a new higher education policy to encourage women to pursue higher education and to reduce drop-outs. It is also recommended that the women should be made owners of assets in the household through legislation.
\end{abstract}

Keywords: Bargaining Power, Education, Ownership of Assets, Gender-Based Violence, Autonomy to Travel Alone, Intra-Household Resource Allocation, Policy Intervention

\section{Introduction}

Important decisions that affect economic development outcomes take place at the household level, including fertility decisions, education of children, labor force participation and production activities at various agricultural and nonagricultural household enterprises [1]. The aspects of intrahousehold resource allocation issues are of potential importance for policy makers for two reasons. First, paying attention to the individual- level welfare, rather than the household-level welfare, may affect the policy makers' views about who and where the poor are. There is possibility, for example, that some households whose average per capita incomes/expenditures are above the poverty line may still contain household members whose standard of living actually falls below the poverty line due to intra-household inequality in resource allocation [2]. Second, the way household members allocate resources among themselves could potentially affect the effectiveness of policy interventions and may even lead to unintended consequences for policy makers.

While neo-classical economic theory has long dealt with social collectivities - firms and households, in particular - it tended to treat them as individual decision-making units, whose internal relations were not part of the economic explanandum. Household behavior was depicted by the behavior of individuals in their capacity as either consumers (the demand for goods and services) or workers (suppliers of labor). This was rectified with the emergence of the "new household economics", whose contribution was to integrate the production and consumption aspects of the household economy and extend maximization principles to its internal workings [3]. The idea that the household represents a locus of economic activity dates back to Chayanov's study of Russian peasants, first published in 1926. However, the economics of the family and the household was fully brought into the mainstream by Gary Becker, the 1992 Nobel Prize winner in economics, in the mid-1960s [4]. The essence of Becker's approach was that, in accordance with a single set of preferences, the household combines time, goods purchased in the market, and goods produced at home to produce commodities that generate utility for the household. Most economists have shared this view of the household. Though this approach originates in standard demand analysis, 
it has been extended to include the determinants of education, health, fertility, child fostering, migration, labor supply, home production, land tenure and crop adoption. Such models are called as "unitary approach" [5]. The unitary approach is also referred to as the "common preferences" model, the "altruism" model, or the "benevolent dictator" model. In the unitary model of the household all members have the same preferences. There is no bargaining process and hence there is no correlation between household expenditures, financial outcomes and who makes the household decisions. Pareto efficiency is reached in these models.

More recently, this model of unitary decision making has been rejected by a number of studies and replaced by nonunitary models [6]; [7]. In the non-unitary models of the household, it is assumed that each household member has a different utility function and therefore has different preferences. A bargaining process takes place within the household and decisions are made according to each member's bargaining power. In these non-unitary models of the household, two factors determine household consumption and expenditures, i.e., each household member's bargaining power and their preferences. The outcome of these bargaining process therefore varies depending on who makes the decisions. The bargaining power depends on the relative income that each partner or household member contributes to the household income. If one partner earns a higher income or receives a positive income shock, this increases their bargaining power and hence the bargaining process with in the household will change in their favor. The control over resources leads to control over decisions [8]. The non-unitary models are called as "collective" models.

The collective approach to the household can be subdivided into two broad categories: those models that rely on cooperative solutions to bargaining among individuals and those that rely on non-cooperative game theory. The cooperative approach begins by noting that individuals form a household when the benefits associated with doing so exceed those obtainable from remaining alone. Broadly speaking there are two types of cooperative approaches. Models that rely on cooperative solutions to bargaining among individuals suppose only that household decisions are always efficient in the Pareto sense [9]; [10]. Whereas, the second category of cooperative models represent household allocations as the outcome of some specific bargaining process and applying to this framework the tools of game theory; [11].

In contrast to cooperative models, the non-cooperative approach does not assume that members necessarily enter into binding and enforceable contracts with each other. They assume that individuals within the household not only have differing preferences but also act as autonomous subeconomies. There are four determinants of bargaining power inside a household. They are control over resources, influences that can impact the bargaining process, interpersonal net works, and basic attitudinal attributes. These resources can be assets, unearned income, transfer payment or welfare receipts. They also explain factors that can influence the bargaining process, such as legal rights, skills and knowledge, education, etc. Self esteem, selfconfidence and emotional satisfaction are attributed to effect bargaining power. There are also other attempts to increase empowerment, such as, legal awareness, political participation and the use of contraceptives.

This study follows the collective non-cooperative model approach to find out the impact of intra-household resources distribution on woman's bargaining power.

Intra-household in-equality in resource distribution is the result of in-equalities in power positions within the household. The factors that affect a woman's bargaining power relate to material and social resources, marital institutions and the agency dimension [12]. Resource dimension includes economic, human as well as social resources [13]. The economic resources are important for women's bargaining power [14]; [15]. The ownership of current assets as a bargaining power indicator is used in various studies and are positively associated with food expenditure [16] and better reproduction decisions [17]. Sons are associated with increasing woman's bargaining position and are important in certain welfare outcomes, such as, a reduction in domestic violence within marriage [18]. A woman's education affects her ownership of health insurance [19]; her nutrient intake [20]; relative reproductive health [21], her ability to negotiate the timing and conditions of sex with partners [22]. The empowerment of women has become an important goal of development policy [23]. The SDGs put great emphasis on equal opportunities for girls and women and on their empowerment. Increasing the resources controlled by women within the household will improve the education and nutrition of children as well as increase spending on long term durable goods. Increased income has an effect on the outcome of the decision process, but also emphasized that information and communication are important for the outcomes of the intra-household decision making [24].

The policy makers expect that women's bargaining power will affect key development outcomes such as the health and education of children and the well-being of the women themselves. Women's bargaining power may affect decisions within the household that impact household production, such as the allocation of labor across various activities, including household chores, agricultural work and wage work [25]. The women's empowerment on the basis of who has the final say on healthcare, large and small household expenditures [26]. Women's bargaining power meant on decision making of four factors: own health; daily household needs, large household purchases and visits to family and relatives [27]. Land ownership reduces women's experiences of domestic violence in India. They used the ownership of land and housing as a measure of bargaining power in India [28]. A broader range of assets was considered moving beyond physical assets to include social networks to examine the impacts on household outcomes and women's well-being [29]. Participation in micro credit projects as a measure of bargaining power and considered its effect on land and asset 
ownership. Whether the mother's first child was a boy and whether she ever gave birth to boy was used as a measure of bargaining power in China [30]. They found that these measures have a positive impact on women's nutrition intake and health outcomes.

Many empirical studies revealed that women's bargaining power in households is that women derive bargaining power from having resources such as income and assets [31]; [32]. Compared to all male property rights, joint property ownership of land and houses improved women's decision making power, their self-confidence and reduced domestic violence [33]. Although women's earnings have a positive impact on their bargaining position, having a relatively good education compared to their partners appears to have a stronger positive impact.

The specific objectives of study are to:

1. Know the impact of education of woman on making consumption allocation decision (bargaining power) in the household.

2. Find out the impact of age, gender, education and income on the asset ownership (bargaining power) of woman.

3. Investigate the impact of asset ownership of woman on gender based violence in household.

4. Research the relationship between asset ownership of woman and the autonomy to travel alone.

5. Investigate the impact of education on the ability of woman to make a decision on the number of children.

\section{Method}

This study was carried out in Kabwe city of Zambia during August and September, 2017. Kabwe city was divided into three zones depending on the level of development - more developed; medium developed and backward. Highridge area was selected from the developed zone; Katondo area was from the medium developed zone and Makululu area from the backward zone. A sample of 50 households from each area, thus a total of 150 households, were selected randomly.

Linear probability model was used to know the factors impacting on the asset ownership of woman, which was treated as the bargaining power of woman in the household. The binary logit model was used to find out the impact of age structure of woman on making consumption allocation decisions, which was treated as the bargaining power of woman in the household. Logit model was used to find out the relationship between asset ownership of woman and gender violence \& autonomy to travel alone. Asset ownership of woman was taken as independent variable and gender violence $\&$ autonomy to travel alone was treated as dependent variables. The data were analysed and the results brought out. The policy conclusions were drawn on the basis of the results.

\section{Result and Discussion}

\subsection{Gender and Age Composition:}

Table 1 shows the details of the heads of the households.

Table 1. Details of the Heads of Households.

\begin{tabular}{llll}
\hline Gender of Head of Household & Frequency & Percentage & Cumulative \\
\hline Male & 114 & 76 & 76 \\
Female & 36 & 24 & 100 \\
Total & 150 & 100 & 100 \\
\hline
\end{tabular}

Source: Primary data.

Table 1 shows that out of 150 sample heads of the households, 114 were male and 36 were female. In percentage terms, they were $76 \%$ and $24 \%$ respectively.

Table 2 shows the age composition of the heads of the households.

Table 2. Age Composition of the Heads of the Households.

\begin{tabular}{llll}
\hline Age group of the head of household & Frequency & Percentage & Cumulative \\
\hline $18-25$ & 6 & 4 & 4 \\
$26-35$ & 50 & 33.33 & 37.33 \\
$36>$ & 94 & 62.67 & 100 \\
Total & 150 & 100 & 100 \\
\hline
\end{tabular}

Source: Primary data.

The table 2 shows that there were 6 heads of households (4\%) in the age group of 18-25 years, 50 heads of households $(33.33 \%)$ in the age group of 26-35 years, and 94 heads of the households were in the age group of above 36 years.

\subsection{Level of Education and Profession of the Heads of the Households}

Table 3 Shows the level of education of the heads of the households. 
Table 3. Level of Education of the Heads of the Households.

\begin{tabular}{llll}
\hline Level of Education of the head of Household & Frequency & Percentage & Cumulative \\
\hline Primary & 28 & 18.67 & 18.67 \\
Secondary & 54 & 36 & 54.67 \\
Tertiary & 56 & 37.33 & 92 \\
Illiterate & 12 & 8 & 100 \\
Total & 150 & 100 & 100 \\
\hline
\end{tabular}

Source: Primary data.

The table 3 shows that out of 150 heads of households 28 (18.67\%) studied up to primary level, 54 (36\%) studied up to secondary level, $56(37.33 \%)$ studied up to tertiary level and the number of illiterates was $12(8 \%)$.

Table 4 shows the profession of the heads of the households.

Table 4. Profession of the Heads of the Households.

\begin{tabular}{llll}
\hline Profession of the head of household & Frequency & Percentage & Cumulative \\
\hline Government & 37 & 24.66 & 24.66 \\
Private & 33 & 22 & 46.66 \\
Self-employed & 67 & 44.66 & 91.32 \\
None & 13 & 8.66 & 8.66 \\
Total & 150 & 100 & 100 \\
\hline
\end{tabular}

Source: Primary data.

Table 4 shows that out of 150 heads of the households $37(24.66 \%)$ were in the government service, $33(22 \%)$ were in the private sector, 67 (44.66\%) were the self-employed and $13(8.66 \%)$ heads of the household do not work.

\subsection{Income of Male and Female Households}

The table 5 shows the income of male and female households.

Table 5. Income of Male and Female Households.

\begin{tabular}{llll}
\hline Monthly Income in Kwacha & Male & Female & Total \\
\hline Nil & $41(44.56)$ & $51(55.44)$ & $92(100)$ \\
$1-500$ & $9(23.07)$ & $30(76.93)$ & $39(100)$ \\
$501-1000$ & $15(48.38)$ & $16(51.62)$ & $31(100$ \\
$1001-2000$ & $20(74.07)$ & $7(25.93)$ & $27(100)$ \\
$2001-3000$ & $49(58.33)$ & $35(41.67)$ & $84(100)$ \\
3001 and Above & $16(59.25)$ & $11(40.75)$ & $27(100)$ \\
\hline
\end{tabular}

Source: Primary data; Figures in the parentheses are percentages.

Table 5 shows that 44.56 percent male and 55.44 percent female household members do not earn any income. The income of 76.93 percent female members is less than $\mathrm{K} 500$, where as it is 23.07 percent for male. The number of male and female, whose income is between $501-1000$, is almost the same. But the number of male, whose income is between 1001-2000; 2001-3000 and 3001 and above, is more than the female.

\subsection{Asset Ownership by Male and Female}

Table 6 shows the asset ownership by male and female in the households

Table 6. Asset Ownership by Male and Female in the Households.

\begin{tabular}{llll}
\hline Ownership of Assets & Frequency & Percentage & Cumulative \\
\hline Male & 23 & 16.43 & 16.43 \\
Female & 117 & 83.57 & 100 \\
Total & 140 & 100 & 100 \\
\hline
\end{tabular}

Source: Primary data. 
Table 6 shows that 84 percent of women own different types of assets and only 16 percent of men owned them.

\subsection{The Impact of Age, Education and Ownership of Assets on Consumption Allocation Decision Power of Woman in the Household}

The table 7 shows the impact of age, education and ownership of assets on Consumption Allocation Decision Power of Woman in the Household.

Table 7. The Impact of Age, Education and Ownership of Assets on Consumption Allocation Decision Power of Woman in the Household.

\begin{tabular}{ll}
\hline VARIABLES & Logit ratio \\
\hline In-charge & \\
$18-25$ years & $10.32^{* *}$ \\
& $(11.25)$ \\
& $13.94^{* *}$ \\
26-35 years & $(15.74)$ \\
& $0.198^{*}$ \\
Primary & $(0.178)$ \\
& 0.219 \\
Secondary & $(0.203)$ \\
& $0.0403^{* * *}$ \\
Tertiary & $(0.0458)$ \\
& $0.201 * *$ \\
Owns a house & $(0.127)$ \\
\hline
\end{tabular}

\begin{tabular}{ll}
\hline VARIABLES & Logit ratio \\
\hline Owns business related assets & $0.213^{* * *}$ \\
& $(0.122)$ \\
Constant & $8.160^{* *}$ \\
& $(8.572)$ \\
Observations & 148 \\
\hline
\end{tabular}

Standard Error in parentheses.

*** $\mathrm{p}<0.01,{ }^{* *} \mathrm{p}<0.05,{ }^{*} \mathrm{p}<0.1$

The binary logistic model used is a logit model. The dependent variable captures whether the woman makes decisions with regards to consumption in the household or not.

The model results show that a woman aged between 26 to 35 years old is 10.32 times more likely to be in-charge of making consumption allocation decisions than a woman aged between 18 to 25 years old.

The findings also suggest that although age gives higher odds ratios, tertiary education is also a factor in a woman's decision making in a household. Other significant factors are whether she owns a house or other type of assets that are business related such as a shop or a saloon.

\subsection{The Impact of Age, Gender, Education and Income on the Asset Ownership of Woman}

The table 8 shows the impact of age, gender, education and income on the asset ownership of woman.

Table 8. The Impact of Age, Gender, Education and Income on the Asset Ownership of Woman.

\begin{tabular}{|c|c|c|c|c|c|c|c|c|}
\hline Source & & SS & & df & & MS & \multicolumn{2}{|c|}{ Number of observations $=140$} \\
\hline 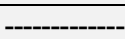 & & -------- & & - & & ------ & \multicolumn{2}{|c|}{$F(4,135)=2.90$} \\
\hline Model & & 1.51976757 & & 4 & & .379941891 & \multicolumn{2}{|c|}{ Prob $>F=0.0244$} \\
\hline Residual & & 17.701661 & & 135 & & .131123415 & \multicolumn{2}{|c|}{ R-squared $=0.0791$} \\
\hline & & -----------' & & & & ------- & \multicolumn{2}{|c|}{ Adj R-squared $=0.0518$} \\
\hline Total & & 19.2214286 & & 139 & & .138283659 & \multicolumn{2}{|c|}{ Root MSE $=.36211$} \\
\hline assets & Coef. & & Std. Err. & & $\mathbf{t}$ & $\mathbf{P}>|\mathbf{t}|$ & \multicolumn{2}{|c|}{ [95\% Conf. Interval] } \\
\hline gender & .1750576 & & .0769656 & & 2.27 & 0.025 & .0228433 & .3272719 \\
\hline education & .0250673 & & .0401132 & & 0.62 & 0.533 & -.0542642 & .1043988 \\
\hline income & .0000349 & & .000016 & & 2.19 & 0.031 & $3.31 \mathrm{e}-06$ & .0000665 \\
\hline cons & .6043072 & & .1669328 & & 3.62 & 0.000 & .2741655 & .9344489 \\
\hline
\end{tabular}

This is a linear probability model. It uses a dependent variable that takes the value of 1 if woman owns assets and 0 if she does not.

The information in the model shows that gender of the head of household and the total income of a household are significant factors in determining the asset ownership by a woman.

\subsection{Impact of Asset Ownership of Woman on Gender-Based Violence in the Household}

Table 9 shows the impact of asset ownership of woman on gender-based violence in the household.
Table 9. Impact of Asset Ownership of Woman on Gender-based Violence in the Household.

\begin{tabular}{ll}
\hline VARIABLES & odds ratio \\
\hline Gender Based Violence & \\
Asset ownership & $0.125 * * *$ \\
& $(0.0656)$ \\
Constant & $2.667 * *$ \\
& $(1.277)$ \\
Observations & 138 \\
\hline Standard error in parentheses. & \\
$* * * \mathrm{p}<0.01, * * \mathrm{p}<0.05, * \mathrm{p}<0.1$. &
\end{tabular}

In table 9 gender based violence is taken as a dependent 
variable and asset ownership as an independent variable. The results suggest that asset ownership is a significant factor in determining gender based violence. A woman who owns any form of assets is 0.125 times more likely not to experience gender based violence compared to a woman without ownership of assets.

\subsection{Impact of Asset Ownership of Woman on Autonomy to Travel Alone}

Table 10 shows the impact of asset ownership of woman on autonomy to travel alone.

Table 10. Impact of Asset Ownership of Woman on Autonomy to Travel Alone.

\begin{tabular}{ll}
\hline VARIABLES & Odds ratio \\
\hline autonomy & \\
Assets ownership & 0.949 \\
& $(0.442)$ \\
Constant & 1 \\
& $(0.426)$ \\
Observations & 137 \\
\hline
\end{tabular}

Standard error in parentheses.

$* * * \mathrm{p}<0.01, * * \mathrm{p}<0.05, * \mathrm{p}<0.1$

Table 10 shows that the asset ownership of a woman has no impact on the autonomy to travel alone. The model shows that the ownership of assets by a woman does not influence the ability of a woman to travel alone.

\subsection{Impact of Education on Bargaining Power of Woman on Number of Children}

Table 11 shows the impact of education on bargaining power of woman on number of children.

Table 11. Impact of Education on Bargaining Power of Woman on Number of Children.

\begin{tabular}{ll}
\hline VARIABLES & Logit ratio \\
\hline Secondary & 2.143 \\
& $(1.043)$ \\
Tertiary & $4.038^{* * *}$ \\
& $(2.009)$ \\
No education & 0.850 \\
& $(0.621)$ \\
Constant & 0.588 \\
& $(0.234)$ \\
Observations & 145 \\
\hline
\end{tabular}

Standard Errors in parentheses.

$* * * \mathrm{p}<0.01, * * \mathrm{p}<0.05, * \mathrm{p}<0.1$ (shows variable significant at the given levels).

The table 11 looks at the effect of education on the ability of a woman to make a decision on the number of children.

The results suggest that only having tertiary education is a significant factor when deciding on the number of children by the woman. A woman with tertiary education is four times more likely to have an influence on the number of children than compared to a woman with primary education only.

\section{Conclusion}

The study concluded that there is positive impact of age on the bargaining power of woman in the household. A woman aged between 26-35 years has more decision power in the consumption allocation than a woman aged 18-25 years. The study revealed that a woman who has tertiary level of education has more decision making power than others. The asset ownership of woman has impact on decision power in the household. These results are in conformity with the results of the study by Dercon (2002) and Doss (1997). The asset ownership of woman (bargaining power) is positively affected by the income of the household. This supports the outcome of the studies by Agarwal (1994); Kabeer (1999); and Quisumbing (2003).

The asset ownership is a significant factor in determining gender-based violence. A woman who owns any form of assets is more likely not to experience gender-based violence compared to a woman without ownership of assets. This confirms the results of the study by Panda and Agarwal (2005) and Datta (2006).

This study found that the asset ownership of a woman has no impact on the autonomy to travel alone. The study revealed that having tertiary education is a significant factor in deciding on the number of children by a woman (bargaining power). This confirms the results of the study by Jejobhoy (1995); Maitra (2003) and Wolff (2000).

The study made the following recommendations.

1. Since the tertiary education had positive impact on the bargaining power of woman, a new higher education policy should be constituted in Zambia to encourage women to pursue higher education and to reduce dropouts to improve gender-equality. The legislation on prohibition of early marriages should be strictly implemented to reduce drop-outs.

2. Asset ownership of woman had positive impact on the bargaining power of woman in the household. The Woman Organizations should educate the women on the importance of ownership of assets to increase their bargaining power to reduce gender-gap. The Government can also make legislation to make women owners of assets in the household.

3. Gender-based Violence is one of the major problems in Zambia. The asset ownership of woman can solve this problem. Hence, Women Welfare Ministry should give emphasis in its policies and programs on creation of assets and making women as their owners.

4. Income had positive impact on bargaining power of woman in the household. The woman should participate in income-generating activities to increase her income. The Government should prepare a policy in which reservation could be provided to women the implementation of all its programs of poverty eradication.

5. Education had positive impact on the ability of woman to make decision on number of children. To control population growth women should be educated. 
Reservation of seats for girls and women should be given at all levels of education system.

\section{References}

[1] Fuwa, N.; Shahidur, R.; Andrew, D.; and Tara Vishwanath (2000): "Intra-household Analysis". In Designing Household survey Questionnaire for Developing Countries: Lessons from 15 years of the Living Standard Measurement Study, ed. Margaret Grosh and Paul Glewwe, Vol. 2, Washington, D. C: World Bank.

[2] Haddad, L. and Kanbur, R. (1990): "How serious is the Neglect of Intra-household Inequality?" Economic Journal 100, No. 402; 866-81.

[3] Kabeer, N. (1991): Gender, Production and Well-being: Rethinking the household Economy, IDS Discussion Paper 288, Institute of Development Studies, England.

[4] Becker, G. S. (1965): A Theory of Allocation of Time. The Economic Journal, 79 (299): 493-517.

[5] Alderman, H.; Pierre-Andre C.; Lawrence H.; John H. and Ravi K.(1995): "Unitary Versus Collective Models of the Household: Is it time to shift the Burden of Proof?" World Bank Research Observer 10, No. 1, 1-19..

[6] Mc. Elroy, M. B., and Horney, M. J. (1981): Nash-bargained Household Decisions: Toward a generalization of the theory of Demand. International Economic Review 22 (2): 333-349.

[7] Mansa, M., and Brown, M. (1980): Marriage and Household Decision-making. A Bargaining Analysis. International Economic Review, 21 (1): 31-44.

[8] Lundberg, S. J., Pollak, R. A., and Wales, T. J. (1997): Do Husbands and Wives Pool their Resources? Evidence from the U.K. child benefit. Journal of Human Resources, 32 (3): 463 480 .

[9] Chiappori, P. (1988): "Rational Household Labor supply". Econometrica 56, No. 1: 63-89.

[10] Browning, M; Francois B.; Pierre-Andre C., and Valerie, L. (1994): "Income and Outcomes: a structural Model of Intrahousehold allocation.”. Journal of Political Economy, 102, No. 6: 1067-96.

[11] Quisumbing, A. R., and Maluccio, J. A. (2003): Resources at Marriage and Intra-household allocation: Evidence from Bangladesh, Ethiopia, Indonesia and South Africa. Oxford Bulletin of Economics and Statistics, 65 (3): 283-327.

[12] Bilisuma, B. D. (2011): Essays on Women's Bargaining Power and Intra-household resource allocation in Rural Ethiopia. International Institute of social Studies, Netherlands.

[13] Kabeer, N. (1999): Resources, Agency, Achievement: Reflections on the Measurement of Women's Empowerment, Development and Change 30 (3), 435-464.

[14] Dercon, S. (2002): Income Risk, Coping Strategies and Safety Nets; The World Bank Economic Observer 17 (2): 141-166.

[15] Duflo, E. (2003): Grandmothers and Granddaughters: Old Age Pension and Intra-household Allocation in South Africa. World bank Economic Review, 17, (1): 1-25.
[16] Doss, C. (1997): The Effects of Woman's Bargaining Power on Household Health and Education Outcomes: Evidence from Ghana: Paper Presented at the Population Association of America Annual Meeting, March 27-29, Washington D. C.

[17] Beegle, K., Frankengerg, E. and Thomas, D. (2000): Bargaining power within couples and Use of Pre-natal and Delivery care in Indonesia: Studies in Family Planning, 32, (2): 130-146.

[18] Schuler, S. R., Hashmi, S. M and Riley, A. P. (1997): The Influence of Women's Changing Roles and Status in Bangladesh's Fertility Transition: Evidence from a Study of Credit Program and Contraceptive use, World Development, 25 (4): 563-575.

[19] Kirigia, J; Sambo, L., Nganda, B., Mwaba, G., Chatora, R., and Mwase, t. (2005): Determinants of Health Insurance Ownership among South African Women, BMC Health Series Research, 5 (17).

[20] Adair, L. (1991): Weight for Height and Body Mass Index in Non-pregnant women. In K. Krasovec and M. A. Anderson (eds.), Maternal Nutrition and Pregnancy outcomes, Washington D. C, Pan American Organization.

[21] Jejobhoy, S. J. (1995): Women's Education, Autonomy and reproduction Behavior; Experience from Developing countries, Oxford, England, Clarendon Press.

[22] Wolff, B., Blank, A. K and Gage, A. G. (2000): Who decides? A Woman's Status and Negotiation of Sex in Uganda. Culture, Health and Sexuality 2 (3), 303-322.

[23] Ute F., Antonia G., and Franzisha H. (2017): Intra-household decision making and Long-term Welfare Effects: New Empirical Evidence.

[24] Ashraf, N. (2009): Spousal Control and Intra-household Decision Making: An experimental study in the Phillippines. American Economic Review, 99 (4): 1245-1277.

[25] Doss, C. (2011): Intra-household Bargaining and resource allocation in Developing countries. Jackson Institute for Global world development Report 2012. Gender Equality and Development.

[26] Allendorf, K. (2007): Do Women's Land Rights Promote Empowerment and Child Health in Nepal, World Development, Elsevier, 35 (11), 1975-88.

[27] Mabsout., R., and Irene Van, S. (2010): Disentangling bargaining Power from Individual and Household level of Institutions: Evidence on Women's position in Ethiopia, World Development 38 (5): 783-796.

[28] Panda, P. and Agarwal, B. (2005): Marital Violence, Human Development and Women's Property Status in India, World Development, 33 (5): 823-850..

[29] Friedman-Sanchez, G. (2006): Assets in Intra-household of Bargaining Among Cut-flower Workers in Colombia, Feminist Economics, 12, (1-2): 247-269.

[30] Wu, Xiaoyu and Lixing, Li. (2011): Gender of Children, Bargaining Power and Intra-household Resource Allocation in China. Journal of Human resources 46 (2), 295-316.

[31] Agarwal, Bina (1994): A Field of One's Own. Gender and Land Rights in South Asia. Cambridge: Cambridge University Press. 
[32] Quisumbing, A. R. and Maluccio, J. A. (2000): Intrahousehold Allocation and gender relations: New Empirical evidence from four Developing Countries. Washington, D. C. International Food Policy research Institute.
[33] Datta, N. (2006): 'Joint Titling - a Win-Win Policy? Gender and Property Rights in Urban Informal settlements in Chandigarh, India'. Feminist Economics 12 (1), pp. 271-298. 